\title{
Damping Evaluation of Linseed Oil-Based Engineering Elastomers by Vibration Response Method
}

\author{
Rakesh Das, ${ }^{1}$ Rajesh Kumar, ${ }^{2}$ and P. P. Kundu ${ }^{1}$ \\ ${ }^{1}$ Department of Polymer Science and Technology, University of Calcutta, 92 A.P.C. Road, Kolkata 700009, India \\ ${ }^{2}$ Precision Metrology Laboratory, Department of Mechanical Engineering, Sant Longowal Institute of Engineering \& Technology, \\ Sangrur, Punjab 148106, India
}

Correspondence should be addressed to P. P. Kundu; chitilekho@gmail.com

Received 21 November 2013; Accepted 16 January 2014; Published 23 February 2014

Academic Editors: B. Hazer and B. Kiskan

Copyright (C) 2014 Rakesh Das et al. This is an open access article distributed under the Creative Commons Attribution License, which permits unrestricted use, distribution, and reproduction in any medium, provided the original work is properly cited.

\begin{abstract}
A low cost experimental setup has been fabricated for evaluation of vibration damping properties of a variety of elastomers developed from linseed oil. Free and forced vibration principles were utilized in this experimental setup. Under forced vibration, the shear loss factor varies from 0.37 to 1.03 at 2 nd bending vibration mode and 0.43 to 0.99 at 3 rd bending vibration mode for different elastomers. The loss factor varies from 0.52 to 0.94 under free vibration. The loss factors determined by both forced and free vibration techniques are in good agreement with the loss factors obtained from dynamic mechanical analysis. The ultimate tensile strength and Young's modulus of the elastomers vary from 0.37 to $3.71 \mathrm{MPa}$ and 0.27 to $10.27 \mathrm{MPa}$, respectively, whereas these properties in compression are in the range of 3.1 to $72.9 \mathrm{MPa}$ and 1.5 to $30.1 \mathrm{MPa}$, respectively. Thus, these elastomers are mechanically stable for vibration damping applications.
\end{abstract}

\section{Introduction}

Most geometric structures and machine elements experience vibratory motion during service or operation. The unwanted vibrations result in fatigue and finally failure of structures, which inevitably cost industries in maintenance, repair, and replacement. Therefore vibration control is a serious engineering challenge. Generally vibration control is achieved by either passive or active damping [1-3]. Passive vibration control involves the modification of stiffness and mass of the vibrating system to make the system less responsive to its vibrating environment. During passive damping treatments, the straightforward solution is the application of materials having high vibration damping capacity, whereas active damping is attained through sensing and activation to suppress the vibration in real time using sensors and actuators, which can be piezoelectric devices [4-6].

During passive damping treatments, elastomers are the most effective and widely used materials due to their unique combination of low modulus and inherent damping properties [7]. Apart from this, many researchers developed polymeric materials like polymer blend and interpenetrating polymer network (IPN) as high performance damping materials $[8,9]$. Natural oils are versatile renewable resources for producing functional polymeric materials [1015] because of their low production cost, universal availability, and biodegradability in nature $[16,17]$. Li and Larock [18] synthesized cationic polymeric materials having good damping behavior of soybean oil and reported the response of damping behavior in the lower frequency range $(1-35 \mathrm{~Hz})$. Also they synthesized cationic polymeric materials from corn and fish oil $[19,20]$ and were characterized through Dynamic mechanical analyzer. In a previous study [21], we developed vibration damping elastomers from linseed oil, most abundant and cheap non edible oil among different natural oil [22]. These elastomers were characterized through the dynamic mechanical analyzer in a wide temperature and frequency range.

Dynamic mechanical analysis (DMA) is very conventional and powerful tool for investigating damping properties of polymeric materials $[23,24]$. In this paper an alternative testing system for determining the dynamic modulus and 
damping loss factor of the polymeric damping materials has been fabricated. This testing system provides a simpler and cheaper method for investigation of the damping behavior of elastomeric materials around room temperature $\left(25^{\circ} \mathrm{C}\right)$. Damping loss factor is defined as the ratio between the energy dissipated within the damping layer and the energy stored in the whole structure, per cycle of vibration [3]. The experimental techniques for determining the dynamic properties of viscoelastic materials were reviewed $[2,3]$. Several methods using the vibration response of test piece under free or forced vibration conditions $[25,26]$ and a modified Oberst beam technique [27] are available to determine the damping loss factor. Also a comparison of different test methods for measuring vibration damping properties of materials has been reported [28]. In this experiment free and forced vibration principle are utilized. In free vibration, square test piece of finite dimension was used and the loss factor was calculated using the logarithmic decrement method [25]. The low frequency vibration response of elastomers was obtained from free vibration. In forced vibration, a sandwiched beam is prepared using elastomer as a core material and the beam is tested through cantilevered vibrating beam technique following ASTM E756-10 [29]. The technique utilizes the elastomeric material to be tested in conjunction with vibrating metal beams either in shear or extension. In this experiment, the elastomers are sandwiched between two metal beams, so the properties are obtained in shear. Shear modulus and shear loss factors are determined from forced vibration response. Also, the frequency response of the materials in the medium frequency range $(1 \mathrm{~Hz}$ to $1 \mathrm{KHz}$ ) is investigated. The disadvantage of higher frequency vibration analysis of cantilevered beam is also elaborated. The experimental loss factor data are compared with the loss factor obtained for these elastomers from the dynamic mechanical analysis. There is no reported work on detailed vibration damping analysis on a wide range of soft viscoelastic materials utilizing vibration response method.

The elastomers are prepared from linseed oil by cationic polymerization technique using styrene (ST) as a comonomer and divinylbenzene (DVB) as a cross-linker. The mechanical properties of rubbers or elastomers are very important for their applications as a shock and vibration absorber elements in machinery and structural engineering, usually at tension, compression, shear load, or combined load conditions. Thus, the elastomers are analyzed in both tension and compression by universal testing machine (UTM). Some important mechanical properties in tension, like Young's modulus, elongation at break, ultimate tensile strength, and toughness are determined. In compression, the significant parameters like Young's modulus, compressive yield strength, ultimate compressive strength, compression at break, and toughness are analyzed.

\section{Experimental}

2.1. Materials. Linseed oil used in our study was obtained from the local market of Kolkata. Styrene (ST), divinylbenzene (DVB) (55 mole \% DVB and 45 mole \%

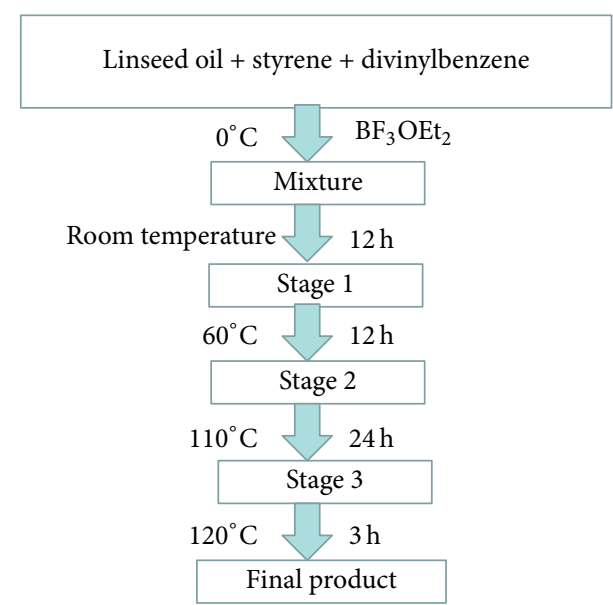

SCHeme 1: Synthesis of cationic polymerization reaction of linseed oil.

ethylvinylbenzene), and boron trifluoride diethyl etherate complex were purchased from Sigma-Aldrich, USA. Methanol, dichloromethane, and concentrated sulfuric acid were purchased from Merck, India. Potassium hydroxide was purchased from SRL Chemical Co, India.

2.2. Synthesis of Elastomers. The elastomers were synthesized by cationic polymerization technique. Boron trifluoride diethyl etherate was used as initiator molecule and it was modified before polymerization to reduce the reactivity of the initiator for homogeneous polymerization. The initiator was modified by mixing at the weight ratio of $3: 5$ with methyl ester of linseed oil with constant stirring at $0^{\circ} \mathrm{C}$. The methyl ester of linseed oil was used instead of regular linseed oil for better miscibility with initiator which caused the uniform distribution of initiator in reaction mixtures.

Methyl ester was prepared in two consecutive steps in a transesterification process using the methodology of the transesterification double step process [30]. Polymeric materials were prepared by heating of the desired concentration of regular linseed oil, styrene, and divinylbenzene in glass molds. The desired amount of styrene and divinylbenzene was added to the linseed oil and the mixture was vigorously stirred. Then, the mixture was cooled and the initiator was added slowly with constant stirring at low temperature. After the homogeneous mixing, the resulting mixture was transferred to glass mold $(300 \times 100 \times 3 \mathrm{~mm})$ and the mold was then sealed with silicon adhesive. After that, the mold was kept at room temperature for 12 hours and then it was heated sequentially at $60^{\circ} \mathrm{C}$ for 12 hours, at $110^{\circ} \mathrm{C}$ for 24 hours, and finally postcured at $120^{\circ} \mathrm{C}$ for 3 hours. In the experiment, the linseed oil content in the original composition of the samples was varied from $45 \%$ to $65 \%$ and in the remaining aromatic content the ST and DVB are taken in fixed internal ratio of $3: 2$ in SET I and $1: 1$ in SET II. The initiator was maintained at $8 \%$ level in all the samples. The reaction for synthesis of elastomers is sketched in Scheme 1 and the detailed feed compositions of different samples are provided in Table 1. 


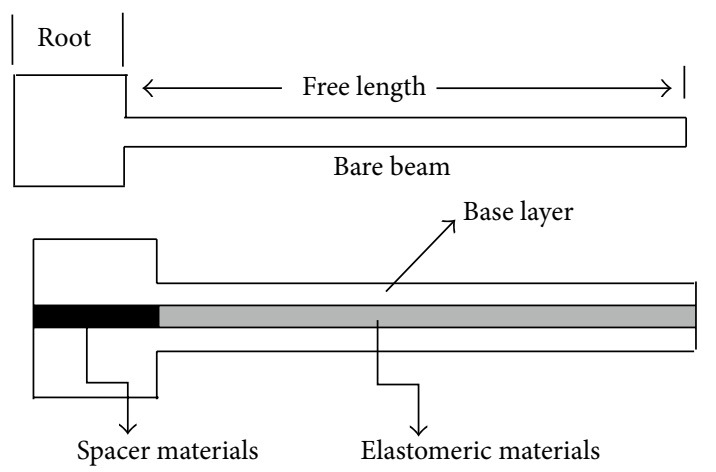

Sandwiched beam

(a)

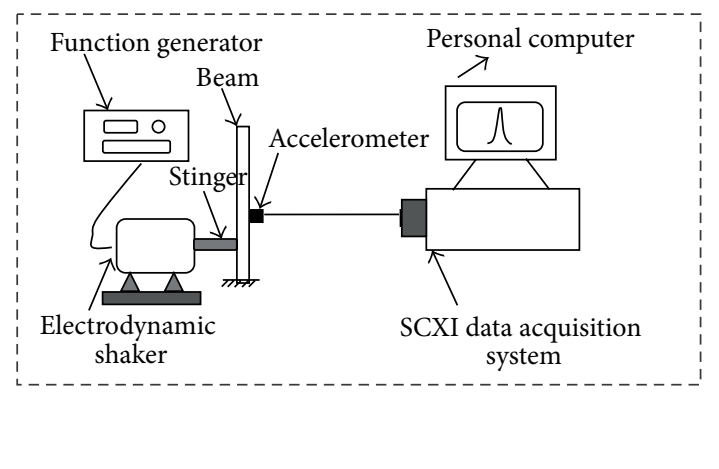

(b)

FIGURE 1: (a) Sketch of the uniform beam, sandwiched beam, and (b) schematic of experimental setup for forced vibration.

TABLE 1: Detailed feed composition of different elastomers.

\begin{tabular}{|c|c|c|c|c|c|}
\hline SET & Sample ID & Linseed oil (\%) & Styrene (\%) & Divinylbenzene (\%) & Initiator (\%) \\
\hline \multirow{5}{*}{ I } & S1Lin 45 & 45 & 28 & 19 & 8 \\
\hline & S2Lin50 & 50 & 25 & 17 & 8 \\
\hline & S3Lin55 & 55 & 22 & 15 & 8 \\
\hline & S4Lin60 & 60 & 19 & 13 & 8 \\
\hline & S5Lin50 & 50 & 21 & 21 & 8 \\
\hline \multirow{3}{*}{ II } & S6Lin55 & 55 & 18.5 & 18.5 & 8 \\
\hline & S7Lin60 & 60 & 16 & 16 & 8 \\
\hline & S8Li565 & 65 & 13.5 & 13.5 & 8 \\
\hline
\end{tabular}

2.3. Tensile Stress-Strain Characterization. The tensile test of the elastomers was conducted under ambient condition according to ASTM D412 using Universal Testing Machine of Lloyd Instruments Ltd, England (Model: LR10 K PLUS). Young's modulus in tension $\left(E_{T}\right)$, ultimate tensile strength $\left(\sigma_{T}\right)$, elongation at break $\left(\varepsilon_{T}\right)$, and toughness were obtained from tensile test.

2.4. Compressive Mechanical Testing. The compressive mechanical test has been performed according to the ASTMD 395-03 specification using a universal testing machine of Tinius olsen, Germany (Model: H 50 KS). Five cylindrical specimens of each sample having $10 \mathrm{~mm}$ diameter and $20 \mathrm{~mm}$ height were tested to get all properties in compression. The Young's modulus in compression $\left(E_{C}\right)$ was obtained from the initial slope of the stress-strain curve. Compressive yield strength $\left(\sigma_{c y}\right)$ is the stress measured at the point of permanent yield, zero slope on the stress-strain curve. Ultimate compressive strength $\left(\sigma_{c u}\right)$ is the stress required to rupture a specimen and it is obtained from the break point of the samples in the compressive test. The compression at break $\left(\varepsilon_{c}\right)$ and the breaking energy or toughness $\left(e_{b}\right)$ that is the energy absorbed per unit volume of the elastomer are also obtained from breaking point.
2.5. Construction of Sandwiched Beam Specimens for Forced Vibration. In this experiment, a uniform beam of mild steel having density $7850 \mathrm{~kg} / \mathrm{m}^{3}$ of dimension $220 \times 15 \times 2 \mathrm{~mm}$ was employed to validate the measurement system, determining Young's modulus of the base layer material (mild steel). In case of sandwiched beam, the synthesized elastomeric material was the core material and mild steel was taken as the base beam material. The core material was cut into a size of $220 \times 15 \times 3 \mathrm{~mm}$ from the original sheet of the elastomeric sample and the dimension of both base layers was $220 \times 15 \times 2 \mathrm{~mm}$. After applying a very thin layer of adhesive on the base layer, the elastomeric material was sandwiched between the two base layers and the sandwiched beam was kept under load for about 6 hours at room temperature $\left(25^{\circ} \mathrm{C}\right)$. The adhesive was selected having Young's Modulus much higher (about ten times) than Young's Modulus of the damping elastomers and the adhesive layer was kept to a minimum (less than $0.05 \mathrm{~mm}$ ) which is very small compared with that of damping materials following the ASTM E75610 [29]. Thus the effect of adhesives is negligible in the experimental results. The Young's modulus of the adhesives was obtained from manufacturer data sheet. The Young's modulus of the adhesive was $979 \mathrm{MPa}$. The Araldite AV8503 Resin with Hardener HV8503 adhesive was used with a proper mixing ratio following the manufacturer's processing 
instruction available in the data sheet. The schematic dimension of the uniform beam and sandwiched beam is shown in Figure 1.

2.6. Fabrication of Experimental Setup and Technique of Forced Vibration. The beam was clamped on its root section in a rigid fixture. The beam was excited by the sinusoidal excitation which is generated by an electrodynamic shaker of Modal Shop Inc., USA (Model K2004E01). The excitation point was kept $15 \mathrm{~mm}$ away from the clamped end of the beam throughout the experiment. The shaker was controlled by the function generator of Agilent Technologies, USA (Model $33220 \mathrm{~A}$ ). In case of uniform beam, a sinusoidal wave form of varying frequency at constant amplitude of $50 \mathrm{mV}$ (R.M.S) and in case of sandwiched beam, an automatic sweep of $50 \mathrm{mV}$ (R.M.S) from $1 \mathrm{~Hz}$ to $1 \mathrm{KHz}$ for 2 minutes duration was applied with the help of a function generator. The response of the beam for 4 minutes was picked up by piezoelectric accelerometer of Metra Mass-und Frequenztechnik, Germany (Model KS94B.100*/01). The accelerometer was connected with data acquisition system of National Instrument, USA (NI SCXI 1530) interfaced with a PC. However the care is to be taken in fixing the accelerometer on the geometrical axis of the beam as well as positioning its way from the nodal points during vibration. The experiment has been performed in 2 nd and the 3 rd mode of vibration. The distance of nodal point from fixed end is 0.783 of the beam length in 2 nd mode. In case of 3rd mode, the distances of the first nodal point and 2nd nodal point are 0.386 and 0.692 , respectively, of the beam length from the fixed end of the beam [31]. The schematic of the experimental setup is shown in Figure 1. The resulting waveform was processed and analyzed by this data acquisition system. The resonance frequency and half power bandwidth for both the base beam and the sandwiched beam are calculated from resulting waveform.

Following the norm, the resonance frequency, $f_{n}$, and bandwidth, $\Delta f_{n}$, of $n$th flexural mode of the uniform beam were estimated from the peak of the resulting waveform and Young's Modulus and loss factor $(\eta)$ of base layer material were deduced from equations [29]:

$$
\begin{gathered}
E=\frac{\left(12 \rho l^{4} f_{n}^{2}\right)}{\left(H^{2} C_{n}^{2}\right)}, \\
\eta=\frac{\Delta f_{n}}{f_{n}},
\end{gathered}
$$

where, $C_{n}$ is the coefficient of the $n$th mode of vibration, $\rho$ is the density of the beam material, $l$ is the length of the beam, and $H$ is the thickness of the beam in the vibration direction.

For sandwiched beam specimen the shear modulus $G_{1}$ and loss factor $\eta_{1}$ of the core elastomeric materials are given by [29]:

$$
\begin{aligned}
G_{1}= & {\left[A-B-2(A-B)^{2}-2\left(A \eta_{s}\right)^{2}\right] } \\
& \times\left[\frac{\left(2 \Pi C_{n} E H H_{1} / l^{2}\right)}{\left\{(1-2 A+2 B)^{2}+4\left(A \eta_{s}\right)^{2}\right\}}\right], \\
\eta_{1}= & \frac{\left(A \eta_{s}\right)}{\left[A-B-2(A-B)^{2}-2\left(A \eta_{s}\right)^{2}\right]}
\end{aligned}
$$

where $A=\left(f_{s} / f_{n}\right)^{2}(2+D T)(B / 2), B=1 /\left[6(1+T)^{2}\right]$, $D=\rho_{1} / \rho,\left[\rho_{1}=\right.$ density of the elastomeric material $], f_{s}=$ resonance frequency for modes of sandwiched beam, $\Delta f_{s}=$ half power bandwidth of modes of composite beam, $\eta_{s}=$ $\Delta f_{s} / f_{s}$, loss factor of sandwiched sample, $s=$ index number: $1,2,3$ and $s=n$, and $T=H_{1} / H$, thickness $\operatorname{ratio}\left(H_{1}\right.$ is the thickness of the elastomeric materials).

The values of $C_{n}$ in different modes of vibration of a cantilever beam are, $C_{1}=0.55959, C_{2}=3.5069, C_{3}=9.8194$, $C_{4}=19.242, C_{5}=31.809$, and $C_{n}=(\pi / 2)(n-0.5)^{2}$, for $n>3$.

2.7. Fabrication of Experimental Setup and Technique of Free Vibration. A square test piece of mild steel and elastomer were tested keeping four ends of the test piece free. The mild steel test piece was tested to validate the experimental setup and technique. The mild steel base plate was fabricated in the size of $100 \times 100 \times 2 \mathrm{~mm}$ having mass per unit area $16.5 \mathrm{~kg} / \mathrm{m}^{2}$. The elastomer was taken on the size of $100 \times 100 \times 3 \mathrm{~mm}$. The test piece was excited at its top middle position by the sinusoidal excitation which was generated by electrodynamic shaker of Modal Shop Inc., USA (Model K2004E01). The shaker was controlled by the function generator of Agilent Technologies, USA (Model 33220A). A sinusoidal waveform of $5 \mathrm{~Hz}$ fixed frequency and constant amplitude of $1.5 \mathrm{~V}$ (R.M.S) was applied with the help of this function generator. The response of the test piece was picked up from its middle position by the piezoelectric light weight accelerometer of Metra Mass-und Frequenztechnik, Germany (Model KS94B. 100*/01). The accelerometer was connected with a digital storage oscilloscope of Aplab Limited, India (Model D36100C) interfaced with the PC, where the resulting waveform is displayed. The schematic of the experimental setup, the excitation point, and detection point of the test piece are shown in Figure 2. The time decay waveform of the test piece was recorded by the oscilloscope and the loss factor is calculated using this waveform. The loss factor is calculated by the logarithmic decrement method using equation [25]:

$$
\eta=2 \zeta=2 \frac{1}{\sqrt{1+(2 \pi / \delta)^{2}}}
$$

where $\delta$ is the logarithmic decrement, defined by

$$
\delta=\frac{1}{r} \ln \left(\frac{A_{i}}{A_{i+r}}\right),
$$




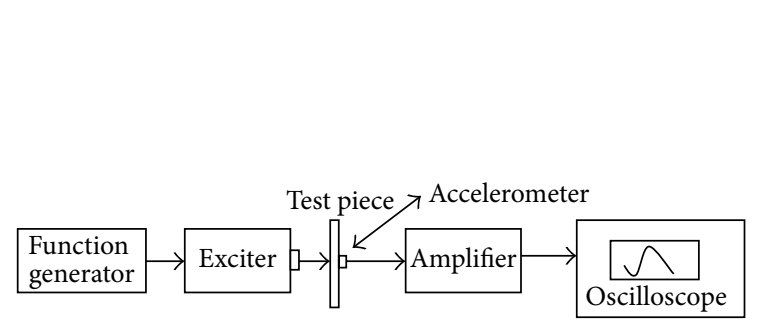

(a)

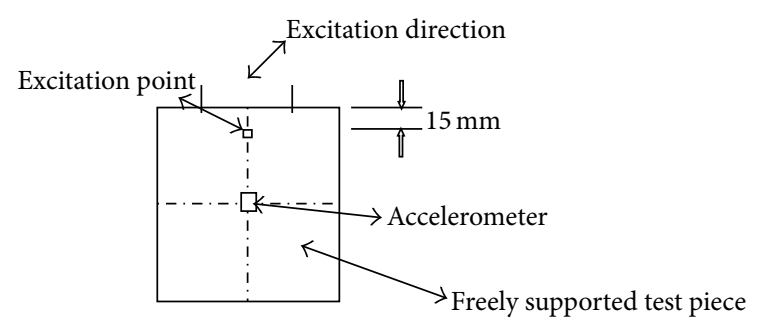

(b)

FIGURE 2: Schematic of the experimental setup for free vibration.

where $r$ is the number of cycles, $\zeta$ is the damping ratio, $A_{i}$ is the first significant amplitude, and $A_{i+r}$ is the amplitude after $r$ cycles.

\section{Results and Discussions}

3.1. Tensile Stress-Strain Characterization. The rubbers or elastomeric materials are extensively used in machinery, building, large civil structures, and so forth as a component of certain energy dissipation devices, dampers, and base isolator to resist external vibrations. These external vibrations are generally induced by several factors such as earthquakes, wind, and rotating machine. Due to large damping and small stiffness of rubber, rubber isolators reduce the mechanical vibrations and transmitted forces from vibrating structures and thus prevent fatal breakdown of the systems. On the other hand the rubber isolator must have a large enough degree of static stiffness because they should support the vibrating structures. The rubber in vibration isolator and damping device are subjected to small oscillatory force superimposed on large static deformation. Thus a systematic performance analysis of the rubber or elastomers are necessary to enrich the knowledge about the damping devices or vibration isolator behavior under different static loading condition. Thus the mechanical behaviors of linseed oil based elastomers under static tension/compression loading condition are analyzed before it's vibration damping characterization.

The tensile stress-strain characterization of the samples of SET I and SET II is shown in Figure 3. The tensile stress-strain curves have two characteristic regions except S4Lin60 of SET I and S7Lin55, S8Lin60 of SET II. At low strains ( $<10 \%)$, the tensile stress rapidly increases with an increase in the strain, but at high strains $(>10 \%)$ the stress increases with strain at a relatively lower rate until fracture occurs. In case of S4Lin60 of SET I and S7Lin55 and S8Lin60 of SET II, the tensile stress increases linearly with strain up to fracture. In tensile stress-strain curves of all samples, there is no clear indication of yield point and strain softening region. Young's modulus in tension $\left(E_{T}\right)$, ultimate tensile strength $\left(\sigma_{T}\right)$, elongation at break $\left(\varepsilon_{T}\right)$, and toughness are reported in Table 2. The crosslinking densities of different elastomers which are calculated from dynamic mechanical analysis [21] have a direct effect on mechanical properties and are also listed in Table 2. From Table 2, it is clear that Young's modulus and ultimate tensile strength are closely related with the concentration of linseed oil. The variation of Young's modulus and ultimate tensile strength with linseed oil concentration is shown in Figure 3. The ultimate tensile strength and Young's modulus decrease with an increase in linseed oil content in the original composition of the samples. With an increase in linseed oil concentration, the DVB concentration decreases, as a result of which, the less cross-linked elastomers are formed. As Young's modulus is improved with cross-linking [32], Young's modulus of the elastomers increases with a decrease in linseed oil content. Cross-linking reduces the molecular mobility of the polymer chain. As a result, the stiffness of the elastomer increases. Under stress conditions, a crack is initiated and it is propagated by taking energy from the external applied force, leading to failure of the material. The higher extent of crosslinking increases the amount of energy required for failure as well as the ultimate tensile strength. Thus, ultimate tensile strength increases with a decrease in linseed oil content.

The elongation at break increases with an increase in linseed oil content in the original composition of elastomers. The presence of higher amount of linseed oil reduces the cross-linking density thereby improves the flexibility of the polymer chain. Thus, elongation at break increases with an increase in linseed oil content in the samples. But, from experimental results, it is evident that in case of S4Lin60 and sample S7Lin60, the elongation of break decreases with an increase in linseed oil content. The linseed oil is grafted in the main polymer chain of ST and DVB. In the resulting elastomers, a certain amount of linseed oil is grafted and the remaining linseed oil remains free. When the linseed oil is taken in higher percentage, a large amount of linseed oil remains unreacted. The increase in free oil indicates that the number of triglyceride chain ends increases. These chain ends are considered as defects or flaws which sometimes dominate in the resulting elastomers by initiating microcracks during tensile test [33]. In case of elastomers containing higher amount of free oil, such cracks may easily initiate which results in a lower elongation at break and tensile strength.

The toughness of the elastomers decreases with an increase in linseed oil content in the original composition of the samples. The toughness is calculated by the amount of energy absorbed per unit volume of the sample under stressed condition until failure. This is measured by the area under the stress-strain curve. The cross-linked part of the elastomer absorbs energy under stressed condition and the absorbed energy increases with an increase in cross-linking. 


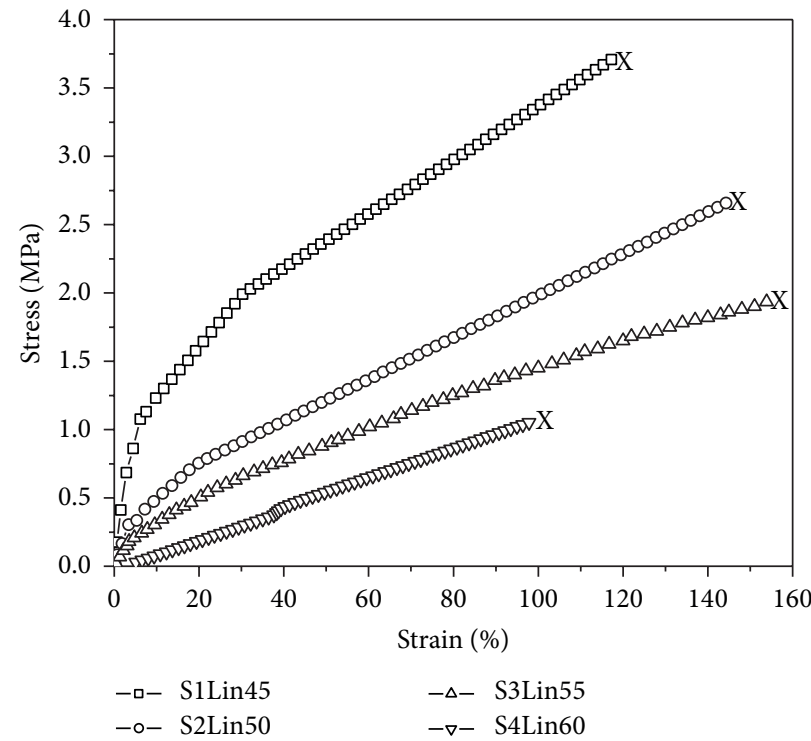

(a)

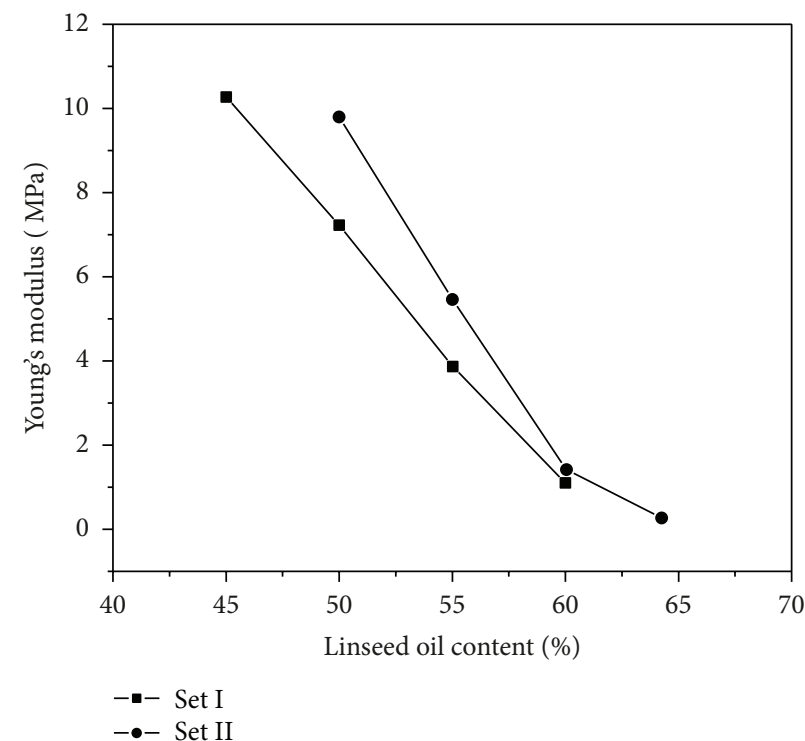

(c)

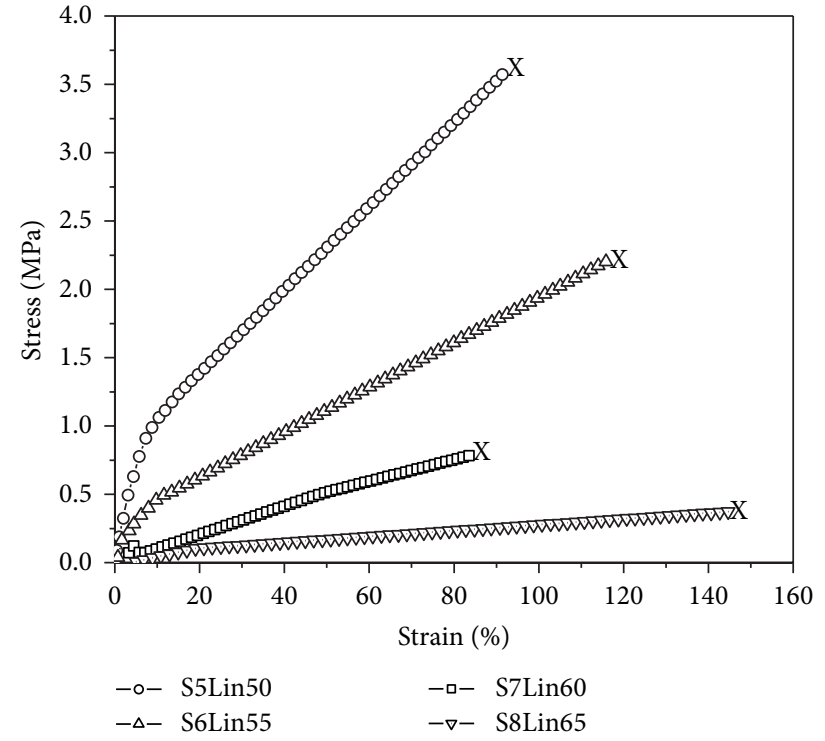

(b)

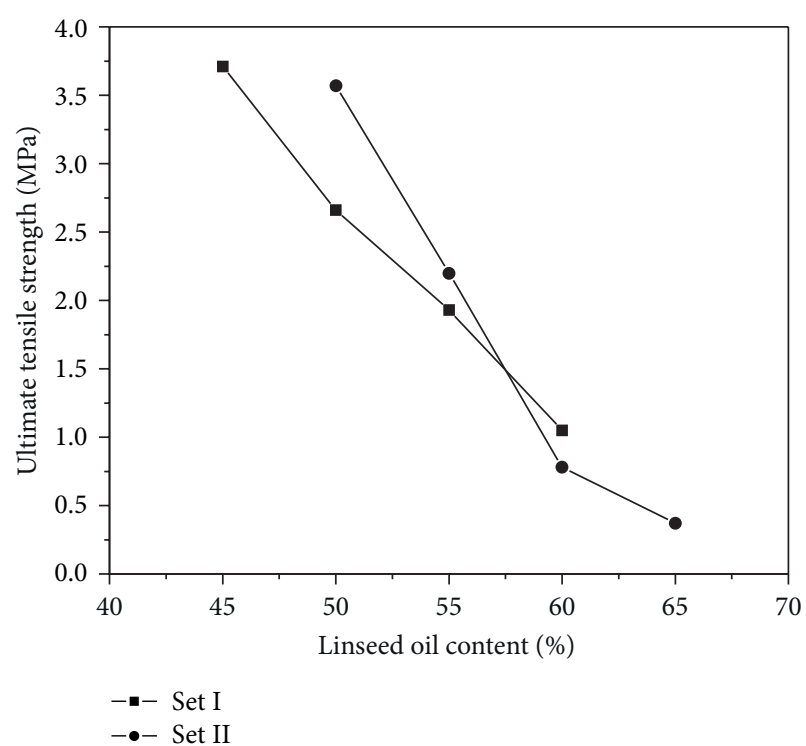

(d)

FIGURE 3: Tensile stress-strain characterization results: (a) tensile stress-strain curve of SET I, (b) tensile stress-strain curve of SET II, (c) variation of Young's modulus with linseed oil content, and (d) variation of ultimate tensile strength with linseed oil content.

TABLE 2: Tensile test results of elastomers.

\begin{tabular}{|c|c|c|c|c|c|c|}
\hline SET & Sample ID & $\begin{array}{l}\text { Crosslinking density } \times 10^{2} \\
\qquad\left(\mathrm{~mol} / \mathrm{m}^{3}\right)[21]\end{array}$ & $\begin{array}{c}\text { Ultimate tensile } \\
\text { strength }\left(\sigma_{T}\right) \\
(\mathrm{MPa})\end{array}$ & $\begin{array}{l}\text { Elongation at break } \\
\left(\varepsilon_{T}\right)(\%)\end{array}$ & $\begin{array}{l}\text { Young's modulus } \\
\left(E_{T}\right)(\mathrm{MPa})\end{array}$ & Toughness (MPa) \\
\hline \multirow{4}{*}{ I } & S1Lin 45 & 4.34 & 3.71 & 117 & 10.27 & 2.88 \\
\hline & S2Lin50 & 3.50 & 2.66 & 144 & 7.23 & 2.16 \\
\hline & S3Lin55 & 2.53 & 1.93 & 154 & 5.54 & 1.78 \\
\hline & S4Lin60 & 1.15 & 1.05 & 98 & 1.10 & 0.51 \\
\hline \multirow{4}{*}{ II } & S5Lin50 & 4.30 & 3.6 & 91 & 9.80 & 1.95 \\
\hline & S6Lin55 & 2.81 & 2.2 & 115 & 5.46 & 1.44 \\
\hline & S7Lin60 & 2.01 & 0.78 & 83 & 1.32 & 0.34 \\
\hline & S8Lin65 & 1.04 & 0.37 & 144 & 0.27 & 0.31 \\
\hline
\end{tabular}




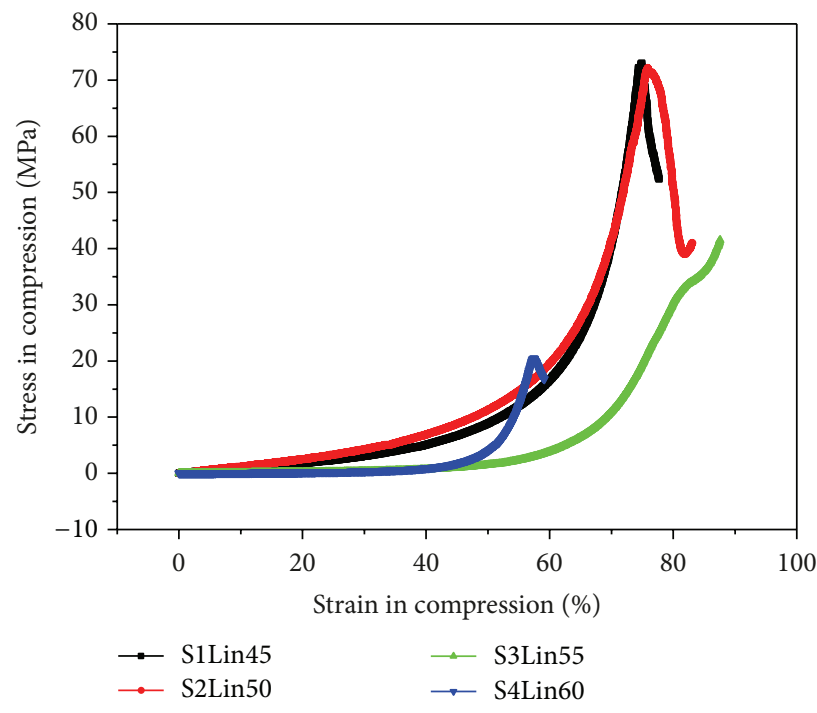

(a)

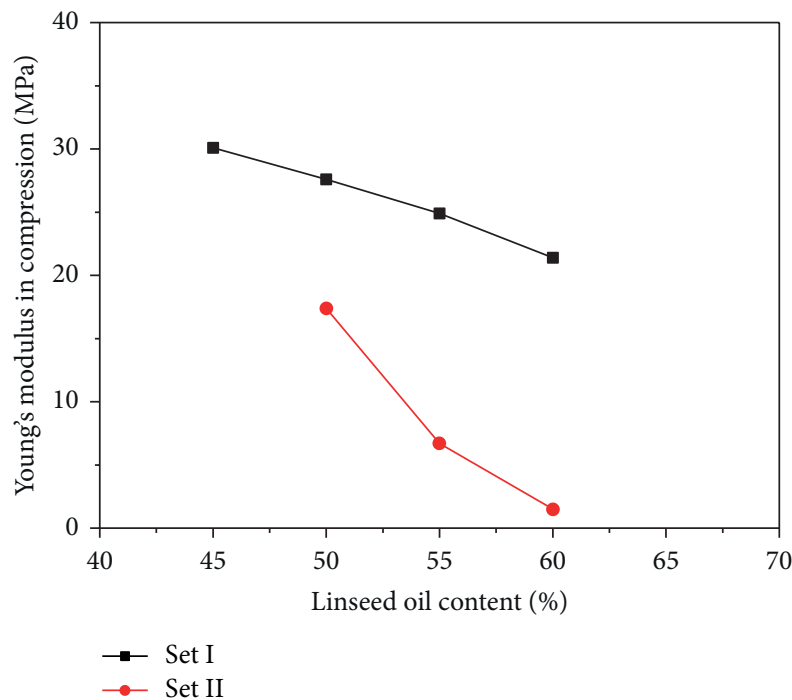

(c)

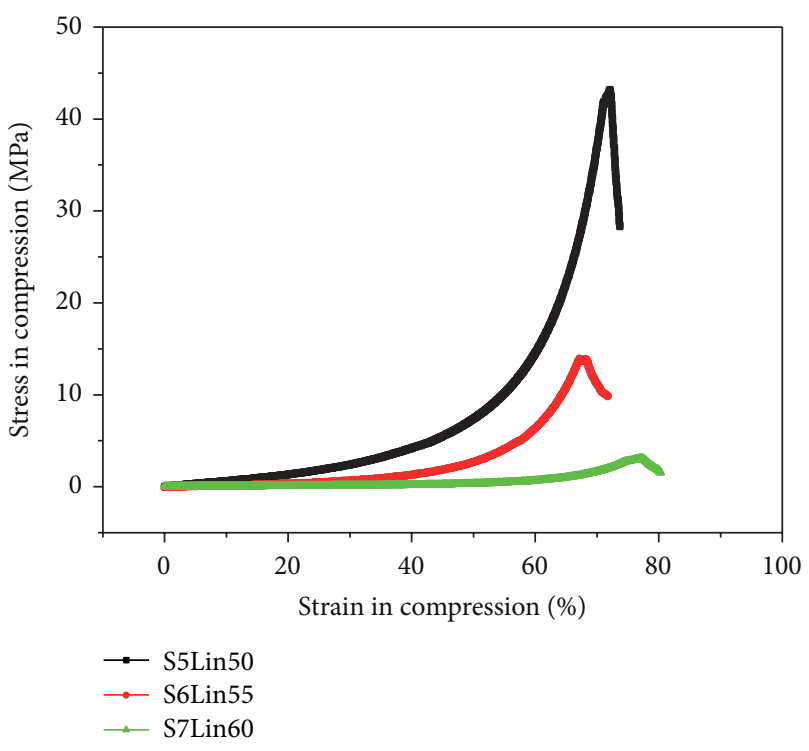

(b)

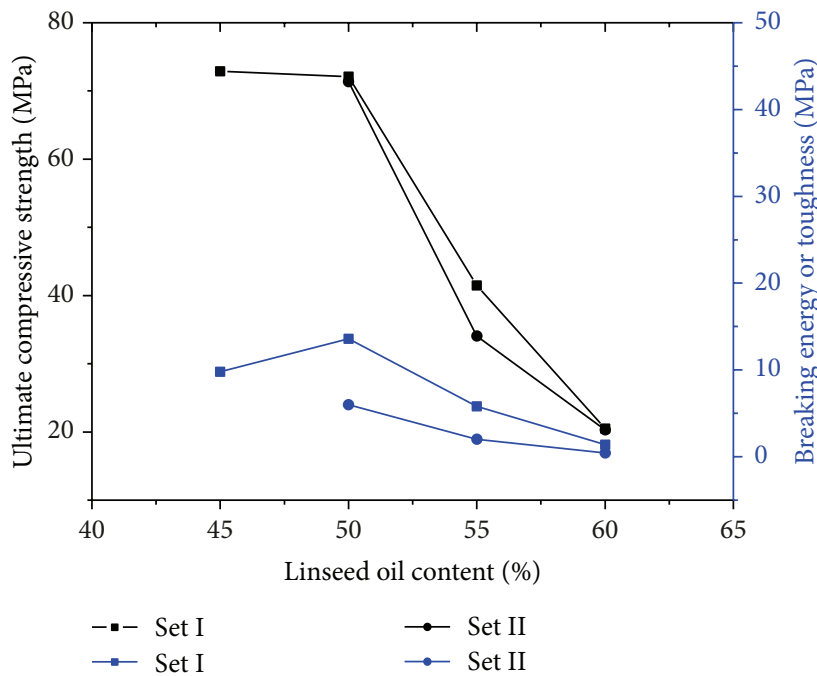

(d)

FIGURE 4: Compression testing results: (a) compressive stress-stress curve of SET I, (b) compressive stress-strain curve of SET II, (c)variation of Young's modulus with linseed oil content, and (d) variation of ultimate compressive strength and toughness with linseed oil content.

Thus toughness decreases with an increase in linseed oil content in the elastomers.

3.2. Compressive Mechanical Analysis of Elastomers. The compressive stress-strain curve of elastomers of SET I and SET II is shown in Figure 4. Young's modulus in compression $\left(E_{C}\right)$, compressive yield strength $\left(\sigma_{c y}\right)$, ultimate compressive strength $\left(\sigma_{c u}\right)$, compression at break $\left(\varepsilon_{c}\right)$, and breaking energy or toughness $\left(e_{b}\right)$ are summarized in Table 3 . Young's modulus in compression is the manifestation of the stiffness of the materials. Stiffness in compression is a very significant parameter in the design approach of dampers in different applications. In Figure 4, the steep nature of the stress-strain curve for S1Lin45, S2Lin50, and S5Lin50 indicates the higher
Young's modulus in compression. From Table 3 it is clear that the Young's modulus decreases from the sample S1Lin 45 to S1lin60 for SET I and from S5 Lin50 to S7Lin60 for SET II. That means Young's modulus in compression decreases with an increase in linseed oil content in the elastomers. The variation of Young's modulus in compression with linseed oil content in the original composition of the samples is shown in Figure 4. Like Young's modulus in tension, Young's modulus in compression also decreases with an increase in linseed oil content. If the S2Lin50 and S5Lin50 are compared, Young's modulus in compression of S2Lin50 is higher than S5Lin50 because higher aromatic content though both contains 50\% linseed oil in the original composition of samples. Young's modulus in compression has the range of $30.1 \mathrm{MPa}$ to $1.5 \mathrm{MPa}$ 


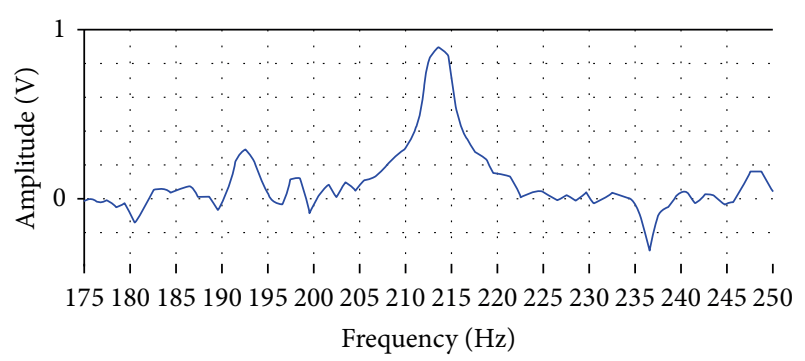

FIGURE 5: Resulting waveform of the base beam in 2nd mode of vibration.

in different elastomers. The Young's modulus in compression is much greater than the Young's modulus in tension. Thus these elastomers are stiffer in compress loading condition than tension.

In the stress-strain curve of Figure 4, the stress increases with strain and becomes maximum at the yield point. The yield point is defined as distinct maximum or the region of strong curvature approaching zero slope in the stress-strain plot [34]. As defined before, the stress corresponding to the yield point is Compressive Yield Strength $\left(\sigma_{c y}\right)$. Compressive Yield Strength $\left(\sigma_{c y}\right)$ and Ultimate compressive strength $\left(\sigma_{c u}\right)$ both follow the same trend as Young's modulus with the variation of linseed oil content in elastomers. The variation of ultimate compressive strength with linseed oil content in the original composition of elastomers is shown in Figure 4. The samples having a higher amount of linseed oil and lower amount of aromatic content require higher amount of applied load to be raptured; thus $\sigma_{c u}$ decreases with an increase in linseed oil content in the original composition of the samples. At rupture, a barreling deformation mode in compression testing is observed with the occurrence of cracks on the bulge surfaces. Thus it is believed the rupture is primarily caused by tensile stress in the circumferential direction at the bulge surface [35]. The rupture or failure point is very important to avoid dangers when the elastomers will be employed under loading conditions in practical applications.

Breaking energy $\left(e_{b}\right)$ or toughness in compression as described before is the area under the stress-starin curve. From Figure 4, it is evident that the area under the stressstrain curve for samples containing higher amount of linseed oil is bigger. From Table 3, it is more evident that the toughness in compression decreases with an increase in linseed oil content in the elastomers as observed in toughness in tension. The variation of toughness with an increase in linseed oil content is shown in Figure 4. The amount of energy absorbed during the break is higher for higher cross-linking structures. Thus this trend is exhibited by elastomers. The toughness has the range of 0.45 to $13.6 \mathrm{MPa}$. The S3Lin 55 has $E_{C}$ value $24.9 \mathrm{MPa}$ and $e_{b}$ has value $5.8 \mathrm{MPa}$ and the S6Lin55 has $E_{C}$ value $6.7 \mathrm{MPa}$ and $e_{b}$ value $2 \mathrm{MPa}$. Thus the sample S3Lin 55 is steeper and tougher than S6Lin55, though both content $55 \%$ linseed oil because of higher cross-linking density.

The mechanical properties obtained from tensile and compressive tests are comparable to different common viscoelastic materials like butyl rubber, nitrile rubber, silicon rubber, and so forth used in vibration damping applications $[2]$.

\subsection{Vibration Damping Properties of Elastomers through} Forced Vibration Technique. The displacement amplitude versus frequency graph for the uniform beam under excitation is shown in Figure 5. In Figure 5, only resonance at the 2 nd mode of vibration is shown. Young's modulus and loss factor of the beam material is determined using (1) at 2nd mode and 3rd mode of vibration of the uniform beam. The result is shown in Table 4 . The time variant displacement waveforms of the cantilevered sandwiched beam using different samples as a core material are shown in Figure 6. In Figure 6, two identical wave forms were obtained, as $2 \mathrm{~min}$ sine sweep of $50 \mathrm{mV}$ (R.M.S) amplitude was applied and the response of the beams was recorded for $4 \mathrm{~min}$. In case of the sandwiched cantilevered beam, the damping of the external excitation applied in it is entirely due to shear in the elastomeric core of the sandwiched beam. When one of the base layers undergoes out of plane bending vibration, the elastomeric core material is forced to deform in shear, because of the upper stiff base layer. As the vibration damping properties of the core materials are very significant, the damping properties of the elastomers comprising varying amount of linseed oil and its effect as a core material in the sandwiched beam are optimized. The shear modulus $\left(G_{1}\right)$ and shear loss factor $\left(\eta_{1}\right)$ of different elastomers determined using (2) as well as natural frequency $\left(f_{s}\right)$, bandwidth $\left(\Delta f_{s}\right)$, and system loss factor $\left(\eta_{s}\right)$ of sandwiched beam in 2 nd and 3 rd mode of vibration are shown in Table 5 . From this Table 5, it is clear that in case of elastomers of SET I and SET II, the shear loss factor improves measurably with an increase in linseed oil concentration and decrease in divinylbenzene concentration in the original composition. The variation of shear loss factor at 2 nd vibration mode with an increase in linseed oil content in the original composition of the elastomers is shown in Figure 7. The three side-chains of linseed triglycerides possess reactive $\mathrm{C}=\mathrm{C}$ bonds and each divinylbenzene molecule has two reactive $\mathrm{C}=\mathrm{C}$ bonds. The DVB takes an important role in the cross-linking of linseed oil polymer during cationic polymerization. Cross-linking plays an important role in determining the damping behavior of the thermosetting materials [34]. When the degree of crosslinking decreases, the damping properties of the polymer improve. Although the sample S2Lin50 and sample S5Lin50 contain $50 \%$ linseed oil, the loss factor of sample S2Lin50 is greater than sample S5Lin50, because sample S2Lin50 has a lesser amount of DVB than sample S5Lin50. The internal ratio of ST and DVB affects the loss factor value. In SET II, the same of amount of ST and DVB was taken. In the prolonged polymerization reaction, a higher amount of reactive DVB is cross-linked with ST and formed the main polymer chain in which the linseed oil is grafted. The loss factor of samples of SET I is higher than the samples of SET II due to the lower amount of DVB present in the polymer chain. The elastomers have two parts: one is comprised of cross-linked polymer chain of ST-DVB in which the linseed oil is grafted and the other unreacted part is comprised of free linseed 


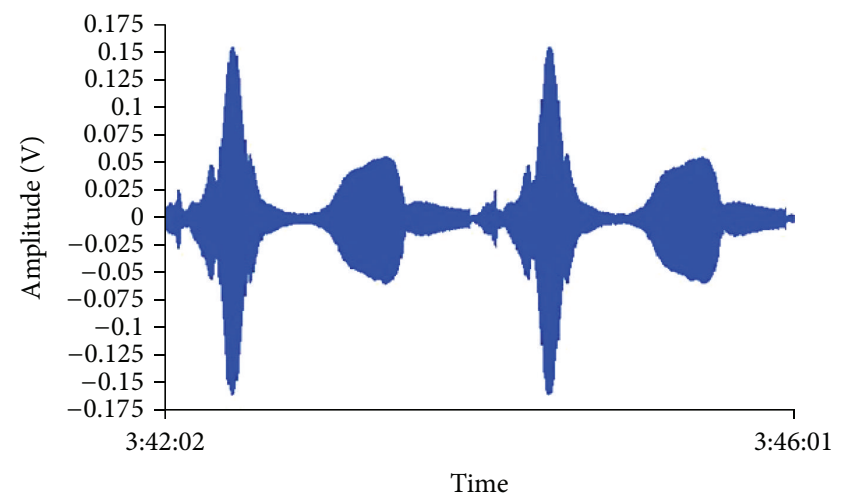

(a)

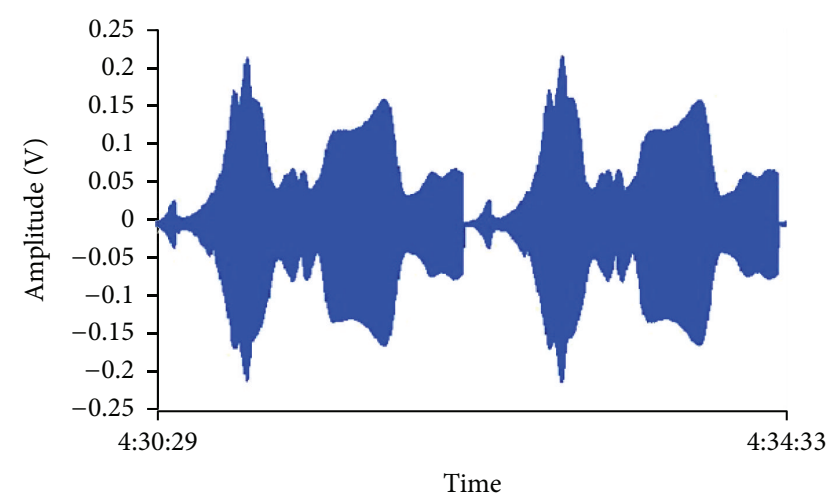

(c)

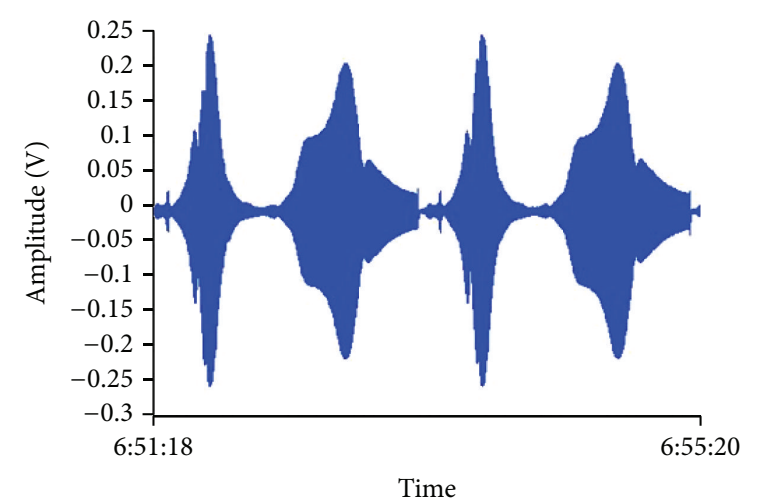

(b)

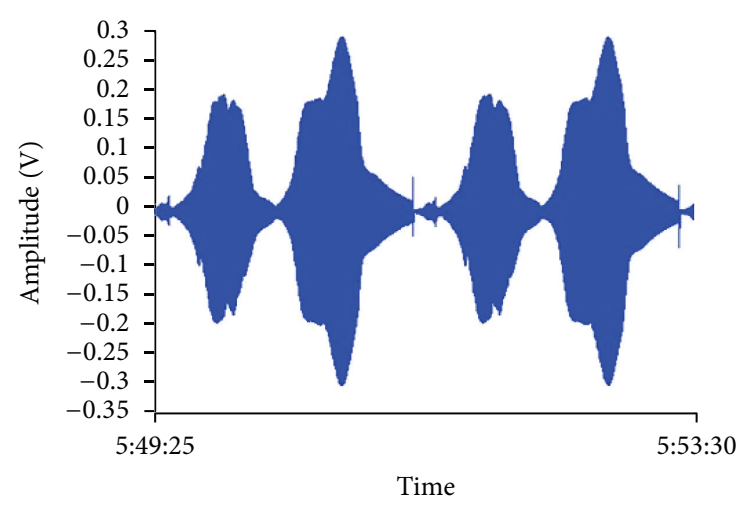

(d)

FiguRE 6: Resulting waveform of the sandwiched cantilevered beams using core materials (a) S3Lin55, (b) S4Lin60, (c) S6Lin55 and (d) S7Lin60.

TABLE 3: Compressive mechanical analysis results of elastomers.

\begin{tabular}{|c|c|c|c|c|c|c|}
\hline SET & Sample ID & $\begin{array}{l}\text { Young's modulus } \\
\quad\left(E_{\mathrm{C}}\right)(\mathrm{MPa})\end{array}$ & $\begin{array}{c}\text { Compressive yield } \\
\text { strength }\left(\sigma_{c y}\right) \\
(\mathrm{MPa})\end{array}$ & $\begin{array}{l}\text { Ultimate } \\
\text { compressive } \\
\text { strength } \\
\left(\sigma_{c u}\right)(\mathrm{MPa}) \\
\end{array}$ & $\begin{array}{c}\text { Compression at } \\
\text { break } \\
\left(\varepsilon_{c}\right)(\%)\end{array}$ & $\begin{array}{c}\text { Breaking energy or } \\
\text { Toughness }\left(e_{b}\right) \\
(\mathrm{MPa})\end{array}$ \\
\hline \multirow{4}{*}{ I } & S1Lin 45 & 30.1 & 72 & 72.9 & 74.6 & 9.8 \\
\hline & S2Lin50 & 27.6 & 58.9 & 72.1 & 70.2 & 13.6 \\
\hline & S3Lin55 & 24.9 & 40.8 & 41.5 & 40.2 & 5.8 \\
\hline & S4Lin60 & 21.4 & 20.5 & 20.5 & 22.5 & 1.4 \\
\hline \multirow{3}{*}{ II } & S5Lin50 & 17.4 & 41.8 & 43.2 & 57.5 & 6 \\
\hline & S6Lin55 & 6.7 & 13.8 & 13.9 & 50.9 & 2 \\
\hline & S7Lin 60 & 1.5 & 3.1 & 3.1 & 52.7 & 0.45 \\
\hline
\end{tabular}

TABLE 4: Forced vibration results of uniform beam.

\begin{tabular}{|c|c|c|c|c|c|c|c|}
\hline \multicolumn{8}{|c|}{ Mode of vibration } \\
\hline \multicolumn{4}{|c|}{ 2nd Mode } & \multicolumn{4}{|c|}{ 3rd Mode } \\
\hline $\begin{array}{l}\text { Resonance } \\
\text { frequency }(\mathrm{Hz})\end{array}$ & Bandwidth $(\mathrm{Hz})$ & $\begin{array}{c}\text { Young's } \\
\text { modulus }(\mathrm{Pa})\end{array}$ & Loss factor & $\begin{array}{c}\text { Resonance } \\
\text { frequency }(\mathrm{Hz})\end{array}$ & Bandwidth (Hz) & $\begin{array}{c}\text { Young's } \\
\text { modulus (Pa) }\end{array}$ & Loss factor \\
\hline 213.3 & 1.2 & $2.05 \times 10^{11}$ & 0.006 & 598 & 3.4 & $2.04 \times 10^{11}$ & 0.006 \\
\hline
\end{tabular}


TABLE 5: Vibration damping characterization results of elastomers and sandwiched beam under forced vibration.

\begin{tabular}{|c|c|c|c|c|c|c|c|c|c|c|c|c|c|}
\hline \multirow{3}{*}{ SET } & \multirow{3}{*}{$\begin{array}{l}\text { Core material of } \\
\text { sandwiched beam }\end{array}$} & \multicolumn{12}{|c|}{ Mode of vibration $(n)$} \\
\hline & & \multicolumn{6}{|c|}{ 2nd mode } & \multicolumn{6}{|c|}{ 3rd mode } \\
\hline & & $\begin{array}{c}f_{s}^{\mathrm{a}} \\
(\mathrm{Hz})\end{array}$ & $\begin{array}{l}\Delta f_{s}^{\mathrm{b}} \\
(\mathrm{Hz})\end{array}$ & $\eta_{s}^{\mathrm{c}}$ & $\eta_{1}^{\mathrm{d}}$ & $\eta^{\mathrm{e}}$ & $\begin{array}{c}G_{1}{ }^{\mathrm{f}} \times 10^{7} \\
(\mathrm{~Pa})\end{array}$ & $\begin{array}{c}f_{s}^{\mathrm{a}} \\
(\mathrm{Hz})\end{array}$ & $\begin{array}{l}\Delta f_{s}^{\mathrm{b}} \\
(\mathrm{Hz})\end{array}$ & $\eta_{s}{ }^{\mathrm{c}}$ & $\eta_{1}^{\mathrm{d}}$ & $\eta^{e}$ & $\begin{array}{c}G_{1}{ }^{\mathrm{f}} \times 10^{7} \\
(\mathrm{~Pa})\end{array}$ \\
\hline \multirow{4}{*}{ I } & S1Lin45 & 277 & 70 & 0.252 & 0.43 & - & 94 & 775 & 192 & 0.25 & 0.43 & - & 250 \\
\hline & S2Lin50 & 271 & 66.5 & 0.245 & 0.49 & - & 63 & 762 & 188 & 0.246 & 0.53 & - & 149 \\
\hline & S3Lin55 & 252 & 60 & 0.238 & 0.71 & - & 40 & 692 & 172 & 0.25 & 0.77 & - & 110 \\
\hline & S4Lin60 & 239 & 44.5 & 0.19 & 1.03 & - & 14 & 672 & 120 & 0.25 & 0.99 & - & 38 \\
\hline \multirow{4}{*}{ II } & S5Lin50 & 279 & 75 & 0.27 & 0.37 & 0.37 & 156 & 778 & 218 & 0.28 & 0.45 & 0.32 & \\
\hline & S6Lin55 & 272 & 73 & 0.27 & 0.53 & 0.50 & 64.7 & 752 & 212 & 0.28 & 0.54 & 0.36 & 201 \\
\hline & S7Lin60 & 258 & 71 & 0.28 & 0.71 & 0.82 & 36 & 732 & 208 & 0.28 & 0.74 & 0.66 & 98.6 \\
\hline & S8Lin65 & 252 & 70 & 0.28 & 0.89 & - & 23.6 & 712 & 196 & 0.28 & 0.99 & - & 53 \\
\hline
\end{tabular}

${ }^{\mathrm{a}}$ Natural frequency of vibration, ${ }^{\mathrm{b}}$ Bandwidth, ${ }^{\mathrm{c}}$ System loss factor, ${ }^{\mathrm{d}}$ Loss factor of core elastomeric materials, ${ }^{\mathrm{e}}$ loss factor of elastomers from dynaic mechanical analysis, ${ }^{\text {f }}$ Shear modulus of core elastomeric materials.

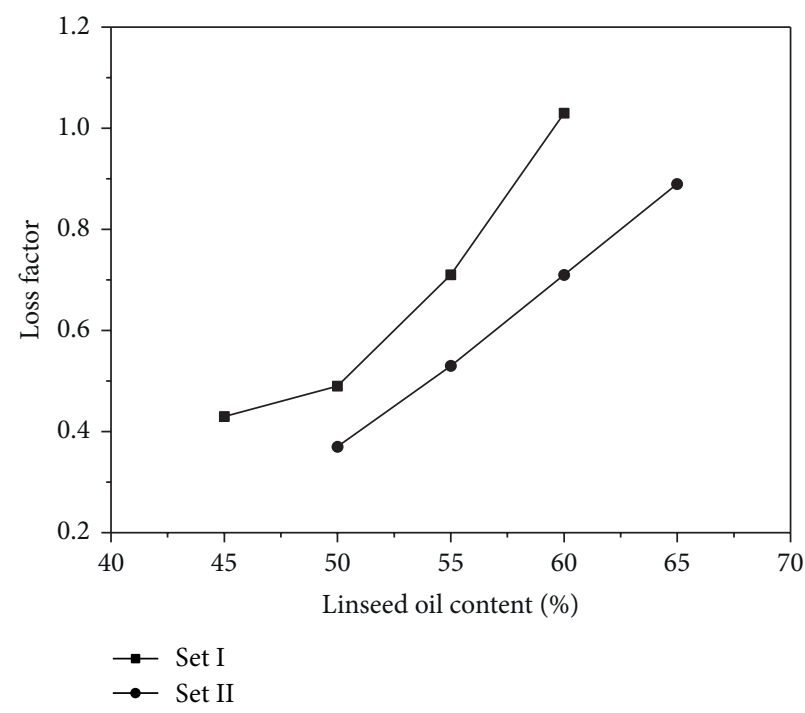

(a)

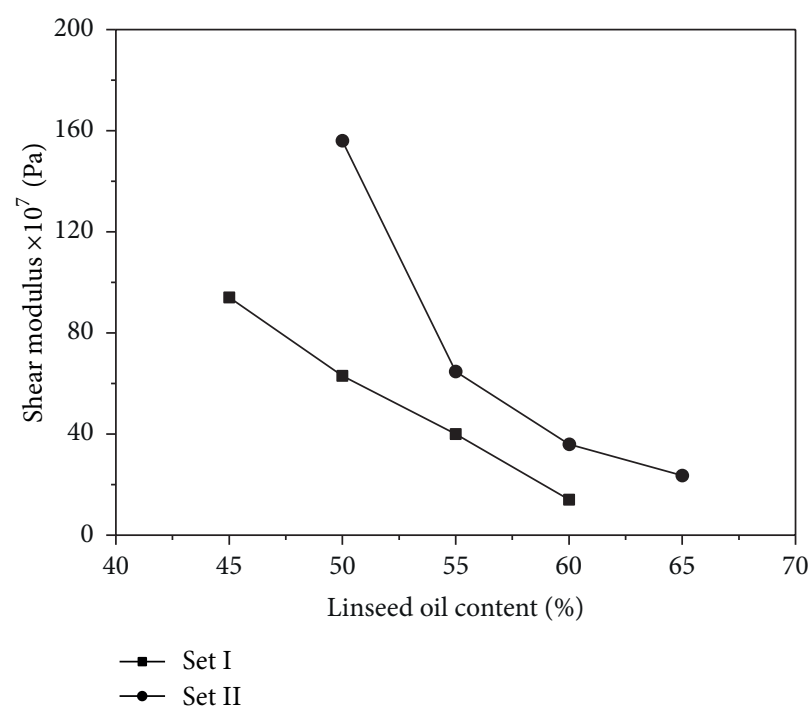

(b)

Figure 7: (a) Variation of shear loss factor with the linseed oil content and (b) variation of shear modulus with linseed oil content.

oil, homopolymer of ST and DVB, and a small proportion of a copolymer of ST-DVB. The unreacted part is viscous and cross-linked part is elastic in nature. The viscous part dissipates energy and the elastic part stores energy during excitation according to the theory of viscoelasticity [2]. The amount of viscous part increases with an increase in linseed oil content in the sample as a result of which the ability of energy dissipation increases during excitation. Thus, loss factor improves with an increase in linseed oil content in the samples. Energy also dissipates in the elastomers because of intermolecular friction and molecular relaxation [36]. In elastomers, the linseed oil segment is flexible, whereas aromatic ST-DVB segment is rigid. Thus, the higher concentration of linseed oil improves segmental mobility of polymer chain as a result of which the ability of an elastomer to dissipate the vibration energy that is the loss factor increases. Also, the ester group of linseed oil present in the polymer chain has a contribution to improve the damping property of elastomers [37]. At the same time, the free oil content in the elastomers which has a direct effect to soften the cross-linked part of the elastomer increases with an increase in linseed oil content in elastomers. Thus, the higher concentration of DVB means the decrease in linseed oil content which increases the degree of cross-linking and restricts the motion of the polymer chain, thereby reducing the damping properties. The loss factor also slightly increases in 3rd bending mode from 2nd bending mode for all samples except S4Lin60 and S8Lin65. The loss factor determined through the fabricated experimental setup has followed the same trend as expected from the theoretical structure-property relationship. The loss factor was evaluated in a wide frequency range in shear mode in cantilevered boundary condition. The beam like specimens are undergoing out of plane sinusoidal vibration applied by vibration exciter. The loss factor was also determined through 
dynamic mechanical analysis (DMA) in shear mode [21]. In shear mode of the DMA, the test piece is however sandwiched between two circular fixed metal plates and the two identical sandwiched systems are mounted on either side of the drive shaft. A sinusoidal shear stress is applied by the motor to the shaft, as a result of which, the specimens undergo a tangential sinusoidal excitation. There is a fundamental difference in the methodology of the two measuring systems. The loss factor for S5Lin50, S6Lin 55, and S7Lin60 obtained from dynamic mechanical analysis is described in Table 5. At 2nd natural frequencies, the loss factors obtained from this fabricated system have a good agreement with shear loss factor obtained from dynamic mechanical analysis but a variation at $3 \mathrm{rd}$ natural frequencies. The room temperature $\left(25^{\circ} \mathrm{C}\right)$ loss factor obtained from this experimental setup has the range of 0.37 to 1.03 in 2 nd vibration mode and the range of 0.43 to 0.99 in the 3 rd vibration mode for different elastomers. As discussed in our another study [21], these loss factors are much higher than minimum required loss factor for effective damping and in some cases higher or comparable to loss factor of universally used damping materials in practical applications like IPN, polymer blend, cross-linked composites, hybrids, and so forth.

From Table 5, it is also clear that the shear modulus decreases with an increase in linseed oil content in the original composition of the polymer sample and this variation is shown in Figure 7. The elastomers containing a low percentage of linseed oil have highly cross-linked rigid polymer chains, because of the higher percentage of the DVB, which causes high resistance under shear during out of plane bending vibration in the sandwiched beam structure. This increases the shear stress and as a result, shear modulus increases. The shear moduli of samples of SET II are higher than SET I because of the higher content of DVB in SET II. Generally, the shear modulus of viscoelastic materials depends upon the frequency and amplitude of excitation. In this experimental procedure, the shear modulus is only dependent on the applied frequency and the shear modulus is calculated in 2 nd mode and $3 \mathrm{rd}$ mode of vibration. The shear modulus also increases in 3rd mode than 2nd mode that is with an increase in frequency which is consistent with dynamic mechanical analysis results [21]. The shear modulus of the sample is closely related to the shear loss factor. The shear loss factor decreases with an increase in the shear modulus. The elastomers having a higher shear modulus store more excitation energy rather than dissipation because of highly cross-linked structure, leading to a decrease in the loss factor.

The natural frequency of the sandwiched beam in 2nd mode and 3rd mode decreases in case of SET I and SET II with an increase in linseed oil content in the core material. The system loss factor $\left(\eta_{s}\right)$ increases slightly in 3rd mode than 2 nd mode. The loss factor of sandwiched beam is maximum when the thickness of the two face layers is the same which is derived by $\mathrm{Li}$ and Crocker [38] following the Ross-Ungar-Kerwin model. In this testing system the two face layers are taken in same thickness. Also the loss factor of this sandwiched structure depends upon different structural parameters like the thickness of core materials, width of the

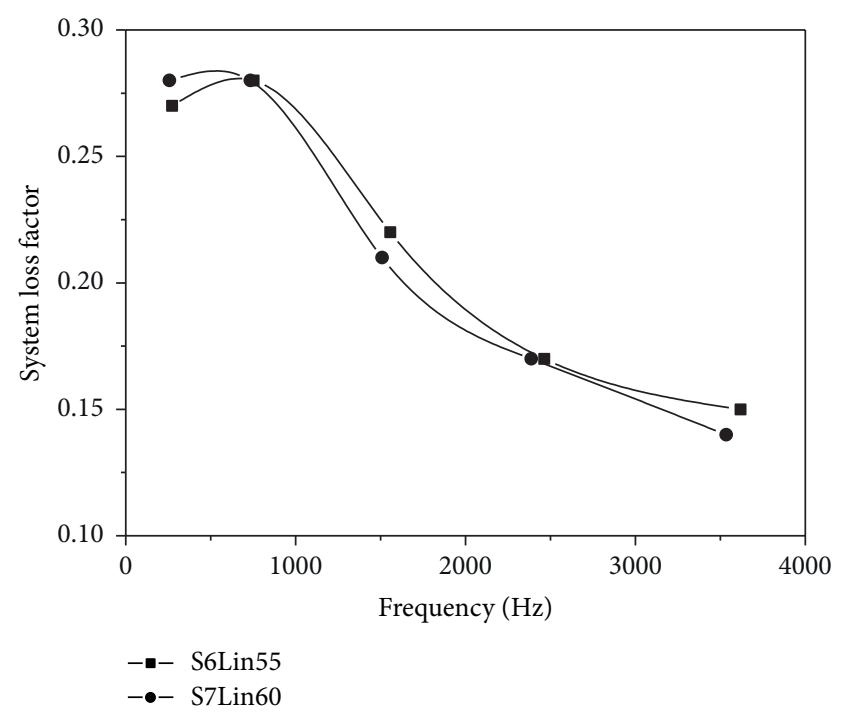

FIGURE 8: Frequency response of system loss factor for sandwiched beam.

beam, and the modulus of the core materials. The frequency response of the sandwiched beams using S6Lin55 and S7 Lin60 is also investigated up to $4 \mathrm{KHz}$ applied frequency and the observation is given in Figure 8. From Figure 8, it is clear that the system loss factor gradually decreases after 3 rd bending mode that is after $1.5 \mathrm{KHz}$ frequency. This trend of loss factor of sandwiched panel is reported by Nilsson [39] when the damping of the core materials is higher than face sheets. Also in this literature [39], it is reported that the maximum response of sandwiched beam exhibits in the mid-frequency range. It is occurred because at the higher frequency, the resonatory behavior of face sheets dominates over the damping behavior of core materials. The bending stiffness of the sandwiched beam can be expressed by [38]

$$
D=2 D_{f}+D_{0}+D_{c},
$$

where $D_{f}$ is the bending stiffness of a face sheet about its own neutral axis, $D_{0}$ is the stiffness of the face sheets associated with bending about the neutral axis of the entire sandwich, and $D_{c}$ is the stiffness of the core. With an increase of frequency the stiffness of the core as well as the face sheets increases. As the core is very soft compared with the face sheets, the stiffness of the face sheets increases more than the core stiffness. At high frequency, the bending stiffness of a face sheet about its own neutral axes that is $D_{f}$ dominants and the total damping is determined by the face sheets $\left(D_{f} \approx D_{0}\right)$. Thus, the system damping decreases at high frequency. For that reason the experiment is performed in the mid-frequency range in which the sandwiched beam exhibits the maximum frequency response and the damping properties of core materials in shear are obtained accurately. The sandwiched structures are used as an effective sound and vibration dampers in a wide variety of engineering applications such as civil, aerospace, automobile, and marine. This sandwiched beam is very effective for tuning of vibration having a particular frequency by suppressing vibration or 

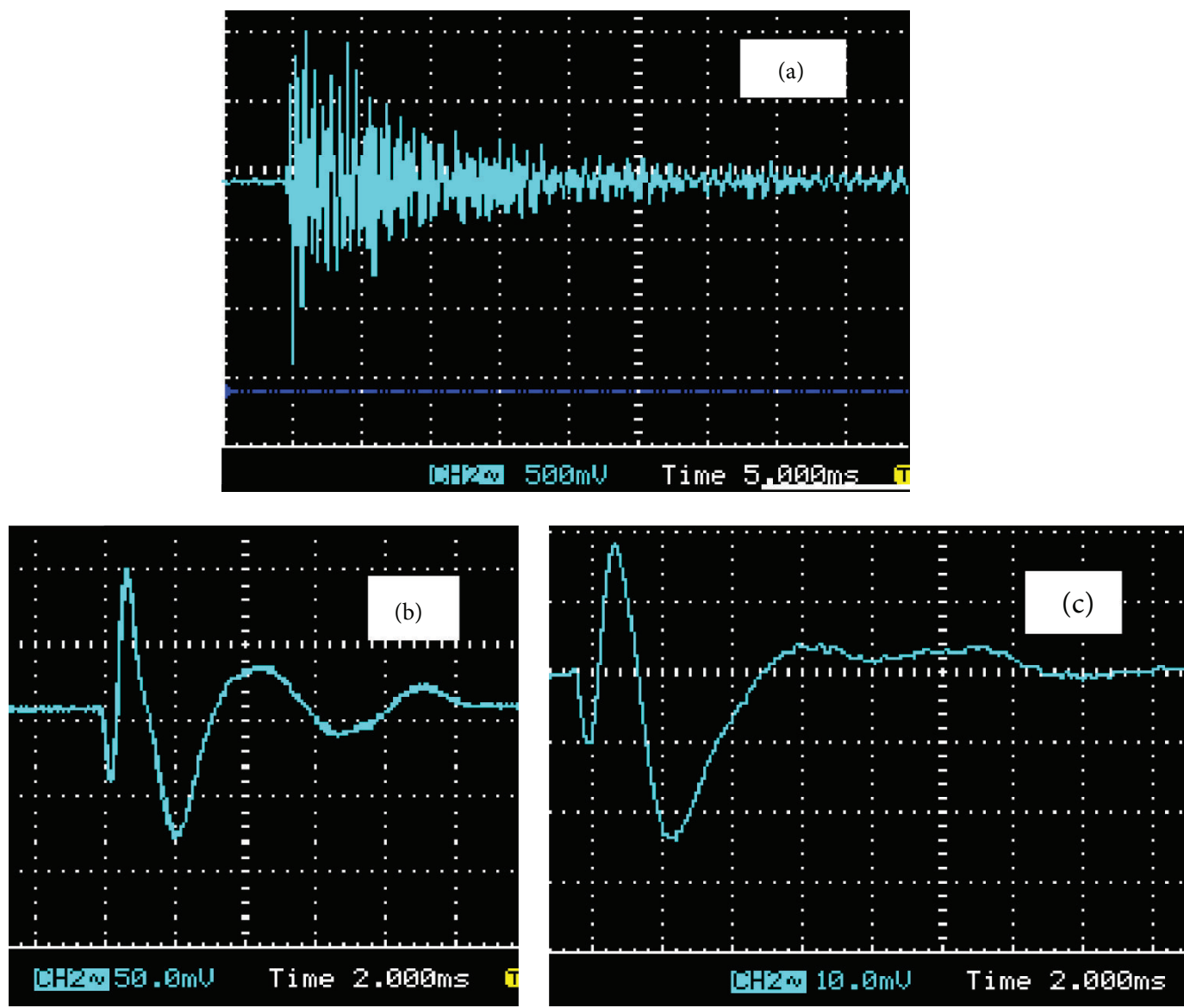

FIGURE 9: The time decay displacement waveform in free vibration. (a) Mild steel, (b) S1Lin45, and (c) S4Lin60.

noise associated with a single frequency or a bandwidth. This structure can also be used to amplify the vibration in other bandwidths.

3.4. Vibration Damping Properties of Elastomers through Free Vibration Technique. The time decay displacement waveforms of mild steel plate and elastomers are shown in Figure 9. The waveform of S1Lin45 and S4Lin60 is the representative waveform of other samples. The room temperature $\left(25^{\circ} \mathrm{C}\right)$ loss factor $(\eta)$ at $5 \mathrm{~Hz}$ fixed frequency calculated from this waveform is shown in Table 6. The mild steel plate behaves as a resonator exhibiting time decay waveform with very negligible decay. The loss factor of mild steel base plate at $5 \mathrm{~Hz}$ frequency is determined as 0.0053 . The time decay waveform of elastomer exhibits very sharp decay within two cycles. But in the case of sample S4Lin60, the waveform is over damped because the initial amplitude of excitation $\left(A_{i}\right)$ is decayed in the very next cycle. The loss factor has the range of 0.52 to 0.94 in the case of samples of SET I and SET II. As the logarithmic decrement method is not applicable in the over damped waveform, the loss factor of S4Lin60 and S8Lin65 is not determined. The loss factor increases with an increase in linseed oil content and a decrease in DVB content in the original composition of the samples as consistent with previous results of forced vibration. Dynamic mechanical analysis (DMA) of these elastomers in tension mode was also studied [21]. In Table 6 , the room temperature $\left(25^{\circ} \mathrm{C}\right)$ loss factor determined from dynamic mechanical analysis at $5 \mathrm{~Hz}$ frequency in tension mode is also reported for comparison. There is a slight variation of results obtained from DMA and results from fabricated experimental setup. In a laboratory investigation of loss factor, it is very difficult to eliminate energy loss to the external environment. There are some factors that should be considered during this experiment. The factors are losses due to attachment of sensing device such as accelerometers and strain gauges; losses due to excitation of sound waves in the atmosphere; and loses due to the interaction of the sample with the supporting structure such as clamp [40]. In our experiment a miniature lightweight $(1.8 \mathrm{~g})$ accelerometer was used to eliminate the losses due to attachment of the accelerometer. The optical vibration sensing device like laser vibrometer is the best solution to eliminate this disturbance. The losses due to excitation of sound waves in the environment dominate in the high frequency range [40]. Here the experiment is performed at a fixed low frequency $(5 \mathrm{~Hz})$. At the low frequency range the structural damping dominates [41]. Two long strings were utilized to suspend the test piece for eliminating support related losses. The low frequency disturbance like earthquake, wind induced vibration, and so forth are very dangerous. Thus the vibration damping properties of elastomers at low frequency range is very important as the elastomers; that is, 
TABLE 6: Vibration damping results of elastomers under free vibration.

\begin{tabular}{lccc}
\hline SET & Sample ID & Loss factor & Loss factor from DMA at $5 \mathrm{~Hz}$ \\
\hline \multirow{2}{*}{ I } & 1 & 0.52 & 0.56 \\
& 2 & 0.78 & 0.87 \\
& 3 & 0.94 & 1.08 \\
\hline \multirow{3}{*}{ II } & 5 & 0.58 & 0.57 \\
& 6 & 0.74 & 0.72 \\
& 7 & 0.8 & 0.86 \\
\hline
\end{tabular}

the viscoelastic materials can be employed as an important component in different damping configurations to control low frequency disturbance.

\section{Conclusions}

An experimental setup for vibration damping characterization of polymers has been fabricated. The vibration damping properties of the elastomers developed from linseed oil have been characterized by this setup. The ultimate tensile strength, Young's modulus, elongation at break, and toughness of the elastomers vary from 0.37 to $3.71 \mathrm{MPa}, 0.27$ to $10.27 \mathrm{MPa}, 83$ to $154 \%$, and 0.31 to $2.88 \mathrm{MPa}$, respectively. Young's moduli in compression and ultimate compressive strength have the range of 1.5 to $30.1 \mathrm{MPa}, 3.1$ to $72 \mathrm{MPa}$, respectively. Thus, these mechanical properties of linseed oil based elastomers are comparable to the commonly used viscoelastic materials such as butyl rubber, nitrile rubber, and silicon rubber for vibration damping applications. From forced vibration damping testing results, it is observed that the shear loss factor of the elastomers are in range of 0.37 to 1.03 at 2 nd bending vibration mode and 0.43 to 0.99 at 3 rd bending vibration mode. The loss factor obtained from free vibration technique varies from 0.52 to 0.94 . The loss factors obtained from both forced and free vibration technique have a good agreement with loss factor obtained from dynamic mechanical analysis results. Thus, it can be concluded that these elastomers can be used as a vibration dampers where vibration and its efficient control are the prime importance for the machinery structures and dynamic systems and also this fabricated experimental setup can be utilized to characterize other polymeric damping materials.

\section{Conflict of Interests}

The authors declare that there is no conflict of interests regarding the publication of this paper.

\section{Acknowledgments}

The financial support jointly from the University Grant Commission (UGC), New Delhi, India under Major research Project scheme (F. no. 36-251(2008) (SR)) and from Technical Education Quality Improvement Project (TEQIP), Government of India are highly acknowledged.

\section{References}

[1] Barber, Handbook of Noise and Vibration Control, Elsevier advanced technology, 1992.

[2] D. I. G. Jones, Handbook of Viscoelastic Vibration Damping, Wiley, New York, NY, USA, 2001.

[3] A. D. Nashif, D. I. G. Jones, and J. P. Henderson, Vibration Damping, Wiley, 1985.

[4] Y. K. Kang, H. C. Park, J. Kim, and S.-B. Choi, "Interaction of active and passive vibration control of laminated composite beams with piezoceramic sensors/actuators," Materials and Design, vol. 23, no. 3, pp. 277-286, 2002.

[5] S. Raja, G. Prathap, and P. K. Sinha, "Active vibration control of composite sandwich beams with piezoelectric extensionbending and shear actuators," Smart Materials and Structures, vol. 11, no. 1, pp. 63-71, 2002.

[6] G. Caruso, S. Galeani, and L. Menini, "Active vibration control of an elastic plate using multiple piezoelectric sensors and actuators," Simulation Modelling Practice and Theory, vol. 11, no. 5-6, pp. 403-419, 2003.

[7] J. A. Harris, "Design principles for vibration isolation and damping with elastomers including nonlinearity," Rubber Chemistry and Technology, vol. 62, no. 3, pp. 515-528, 1989.

[8] N. Yamada, S. Shoji, H. Sasaki et al., "Developments of high performance vibration absorber from poly (vinyl chloride)/chlorinated polyethylene/epoxidized natural rubber blend," Journal of Applied Polymer Science, vol. 71, no. 6, pp. 855-863, 1999.

[9] C.-L. Qin, W.-M. Cai, J. Cai, D.-Y. Tang, J.-S. Zhang, and M. Qin, "Damping properties and morphology of polyurethane/vinyl ester resin interpenetrating polymer network," Materials Chemistry and Physics, vol. 85, no. 2-3, pp. 402-409, 2004.

[10] F. Li, M. V. Hanson, and R. C. Larock, "Soybean oildivinylbenzene thermosetting polymers: synthesis, structure, properties and their relationships," Polymer, vol. 42, no. 4, pp. 1567-1579, 2001.

[11] J. La Scala and R. P. Wool, "Property analysis of triglyceridebased thermosets," Polymer, vol. 46, no. 1, pp. 61-69, 2005.

[12] J. Lu and R. P. Wool, "Novel thermosetting resins for SMC applications from linseed oil: synthesis, characterization, and properties," Journal of Applied Polymer Science, vol. 99, no. 5, pp. 2481-2488, 2006.

[13] S. N. Khot, J. J. Lascala, E. Can et al., "Development and application of triglyceride-based polymers and composites," Journal of Applied Polymer Science, vol. 82, no. 3, pp. 703-723, 2001.

[14] Y. Lu and R. C. Larock, "New hybrid latexes from a soybean oil-based waterborne polyurethane and acrylics via emulsion polymerization," Biomacromolecules, vol. 8 , no. 10, pp. 3108 3114, 2007.

[15] Y. Lu and R. C. Larock, "Soybean-oil-based waterborne polyurethane dispersions: effects of polyol functionality and hard segment content on properties," Biomacromolecules, vol. 9, no. 11, pp. 3332-3340, 2008.

[16] Y. Xia and R. C. Larock, "Vegetable oil-based polymeric materials: synthesis, properties, and applications," Green Chemistry, vol. 12, no. 11, pp. 1893-1909, 2010.

[17] J. C. Ronda, G. Lligadas, M. Galià, and V. Cádiz, "Vegetable oils as platform chemicals for polymer synthesis," European Journal of Lipid Science and Technology, vol. 113, no. 1, pp. 46-58, 2011. 
[18] F. Li and R. C. Larock, "New soybean oil-styrene-divinylbenzene thermosetting copolymers-IV. Good damping properties," Polymers for Advanced Technologies, vol. 13, no. 6, pp. 436-449, 2002.

[19] F. Li, J. Hasjim, and R. C. Larock, "Synthesis, structure, and thermophysical and mechanical properties of new polymers prepared by the cationic copolymerization of corn oil, styrene, and divinylbenzene," Journal of Applied Polymer Science, vol. 90, no. 7, pp. 1830-1838, 2003.

[20] F. Li, A. Perrenoud, and R. C. Larock, "Thermophysical and mechanical properties of novel polymers prepared by the cationic copolymerization of fish oils, styrene and divinylbenzene," Polymer, vol. 42, no. 26, pp. 10133-10145, 2001.

[21] R. Das, R. Kumar, and P. P. Kundu, "Vibration damping characterization of linseed oil based elastomers for its effectiveness to attenuate structural vibration," Journal of Applied Polymer Science, vol. 130, no. 5, pp. 3611-3623, 2013.

[22] C. Stenberg, M. Svensson, and M. Johansson, "A study of the drying of linseed oils with different fatty acid patterns using RTIR-spectroscopy and chemiluminescence (CL)," Industrial Crops and Products, vol. 21, no. 2, pp. 263-272, 2005.

[23] K. P. Menard, Dynamic mechanical analysis: a practical introduction, CRC press, 2008.

[24] L. E. Nielsen, Mechanical Properties of Polymers and Composites, Dekker, New York, NY, USA, 1974.

[25] W. De Silva, Vibration Damping, Control and Design, CRC Press, 2007.

[26] K. A. Alnefaie, S. M. Aldousari, and U. A. Khashaba, "New development of self damping MWCNT composites," Composites $A$, vol. 52, pp. 1-11, 2013.

[27] J.-L. Wojtowicki, L. Jaouen, and R. Panneton, "New approach for the measurement of damping properties of materials using the Oberst beam," Review of Scientific Instruments, vol. 75, no. 8, pp. 2569-2574, 2004.

[28] R. Pereira, J. P. Arenas, and E. Zumelzu, "Comparison of four test methods to measure damping properties of materials by using piezoelectric transducers," Materials and Design, vol. 32, no. 4, pp. 2423-2428, 2011.

[29] ASTM E756-10, Standard Test Method for Measuring VibrationDamping Properties of Materials, American Society for Testing and Materials, 2010.

[30] B. H. Hameed, L. F. Lai, and L. H. Chin, "Production of biodiesel from palm oil (Elaeis guineensis) using heterogeneous catalyst: an optimized process," Fuel Processing Technology, vol. 90, no. 4, pp. 606-610, 2009.

[31] M. Harris and A. G. Piersol, Harris' Shock and Vibration Handbook, McGraw-Hill, New York, NY, USA, 2002.

[32] H. F. Schnell, D. Göritz, and E. Schmid, "The influence of a new chemical cross-link system on the mechanical behaviour of aliphatic polyamides," Journal of Materials Science, vol. 26, no. 3, pp. 661-668, 1991.

[33] T. A. C. Flipsen, R. Derks, H. Van Der Vegt, R. Stenekes, A. J. Pennings, and G. Hadziioannou, "Densely crosslinked polycarbosiloxanes. II: thermal and mechanical properties," Journal of Polymer Science B, vol. 35, no. 9, pp. 1311-1331, 1997.

[34] L. E. Nielsen and R. F. Landel, Mechanical Properties of Polymers and Composites, 1994.

[35] H. A. Kuhn, P. W. Lee, and T. Erturk, "A fracture criterion for cold forming," Journal of Engineering Material Technology, vol. 1995, no. 4, pp. 213-218, 1973.
[36] Y. C. Chern, S. M. Tseng, and K. H. Hsieh, "Damping properties of interpenetrating polymer networks of polyurethanemodified epoxy and polyurethanes," Journal of Applied Polymer Science, vol. 74, no. 2, pp. 328-335, 1999.

[37] M. C. O. Chang, D. A. Thomas, and L. H. Sperling, "Group contribution analysis of the damping behavior of homopolymers, statistical copolymers, and interpenetrating polymer networks based on acrylic, vinyl, and styrenic mers," Journal of Polymer Science B, vol. 26, no. 8, pp. 1627-1640, 1988.

[38] Z. Li and M. J. Crocker, "Effects of thickness and delamination on the damping in honeycomb-foam sandwich beams," Journal of Sound and Vibration, vol. 294, no. 3, pp. 473-485, 2006.

[39] A. C. Nilsson, "Wave propagation in and sound transmission through sandwich plates," Journal of Sound and Vibration, vol. 138, no. 1, pp. 73-94, 1990.

[40] D. L. Russel, "Remarks on experimental determination of modal damping rates in elastic beams," in Vibration and Damping in Distributed Systems-WKB and Wave Methods, Visualization and Experimentation, G. Chen and J. Zhou, Eds., vol. 2, chapter 5, CRC Press, Toyko, Japan, 1993.

[41] M. P. Norton and D. G. Karczub, Fundamentals of Noise and Vibration Analysis for Engineers, Cambridge University Press, 2003. 

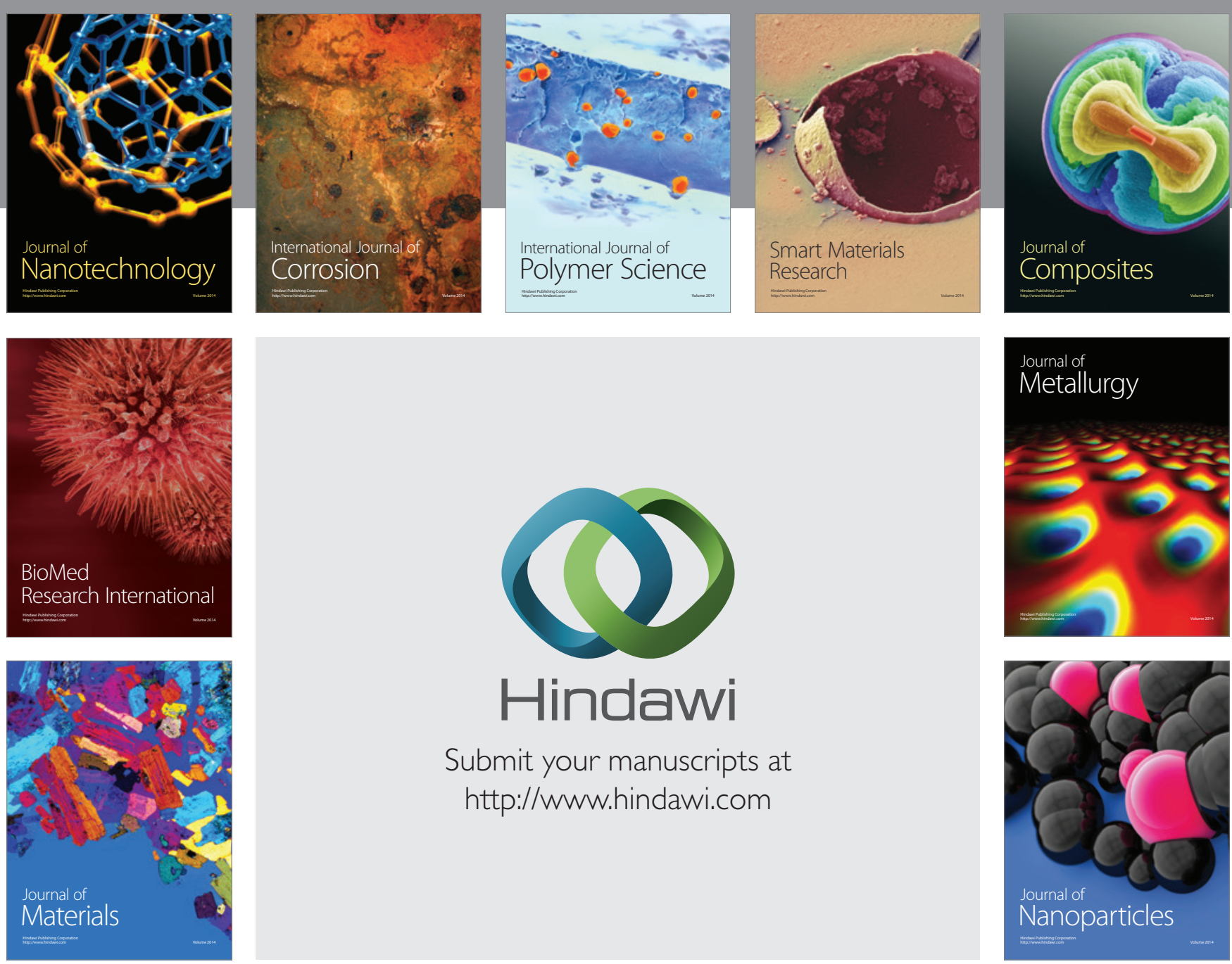

Submit your manuscripts at http://www.hindawi.com
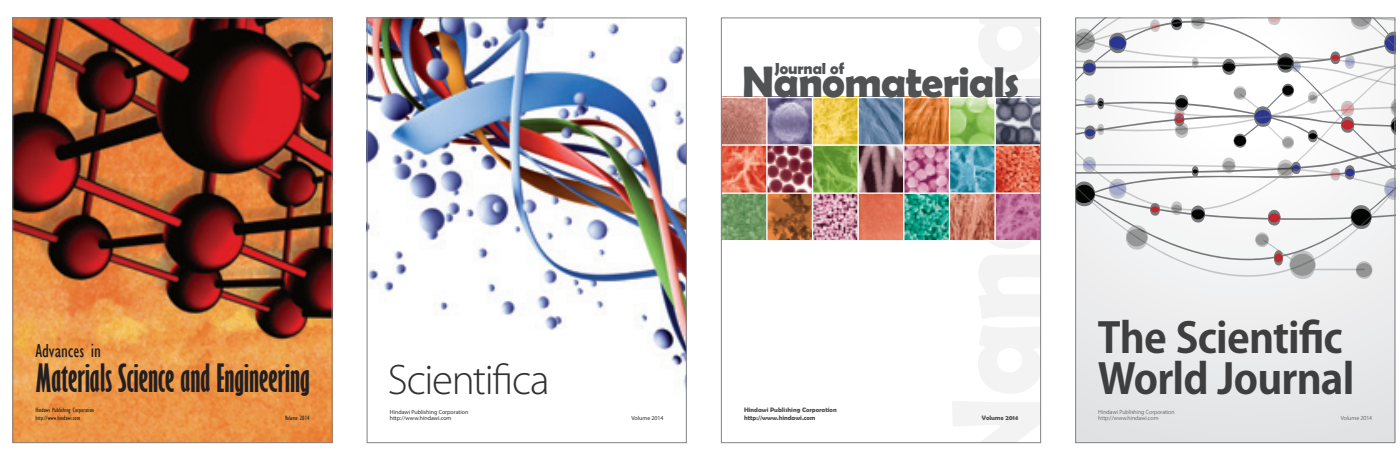

\section{The Scientific World Journal}
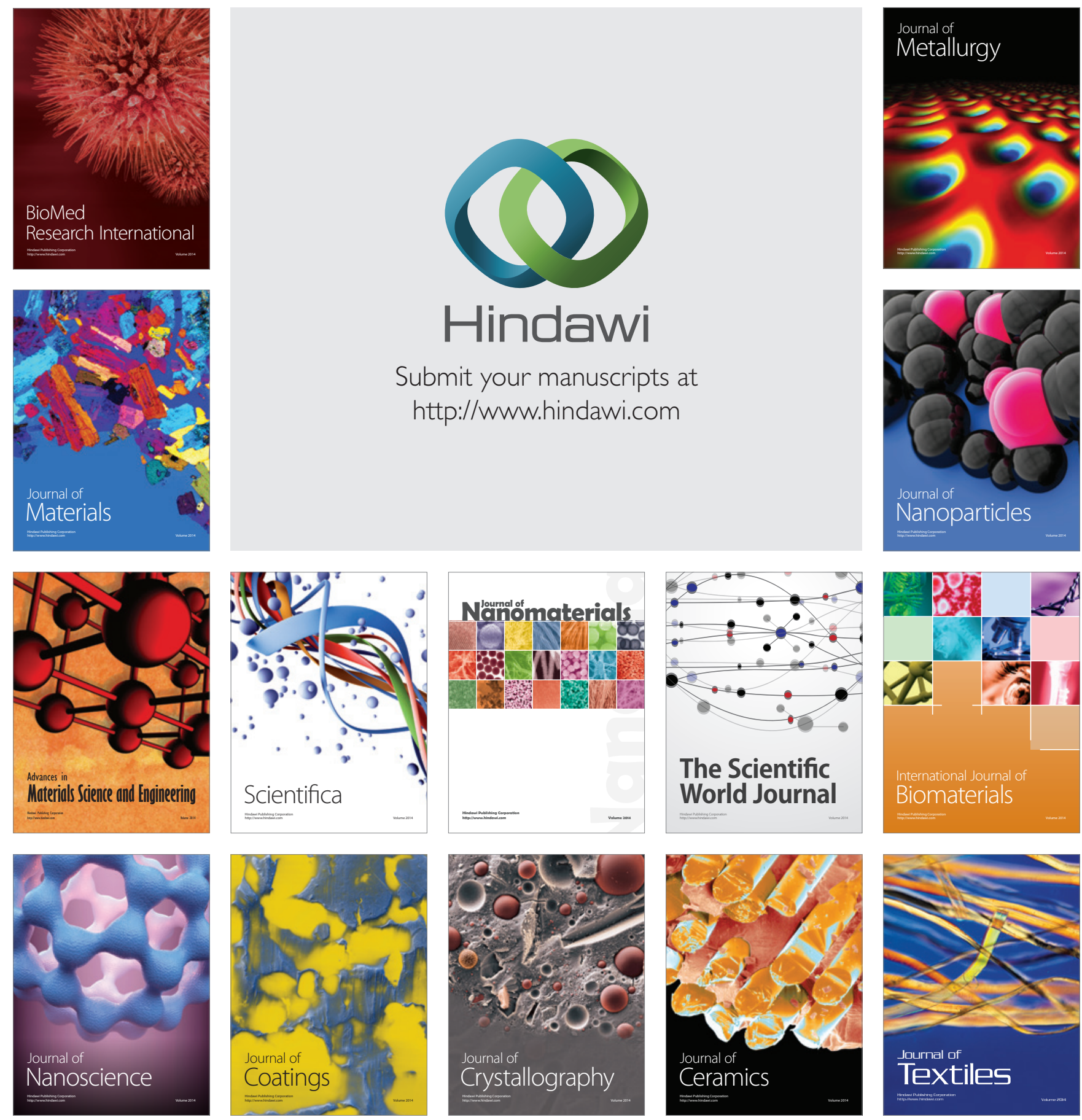